University of New Orleans

ScholarWorks@UNO

2003

\title{
Ultrafine NiFe204 powder fabricated from reverse microemulsion process
}

Jiye Fang

Narayan Shama

Le Duc Tung

Eun Young Shin

Charles J. O'Connor

University of New Orleans

See next page for additional authors

Follow this and additional works at: https://scholarworks.uno.edu/phys_facpubs

Part of the Materials Science and Engineering Commons, Nanoscience and Nanotechnology Commons, and the Physics Commons

\section{Recommended Citation}

J. Appl. Phys. 93, 7483 (2003)

This Article is brought to you for free and open access by the Department of Physics at ScholarWorks@UNO. It has been accepted for inclusion in Physics Faculty Publications by an authorized administrator of ScholarWorks@UNO.

For more information, please contact scholarworks@uno.edu. 


\section{Authors}

Jiye Fang, Narayan Shama, Le Duc Tung, Eun Young Shin, Charles J. O'Connor, Kevin L. Stokes, Gabriel Caruntu, John B. Wiley, Leonard Spinu, and Jinke Tang 


\title{
Ultrafine $\mathrm{NiFe}_{2} \mathrm{O}_{4}$ powder fabricated from reverse microemulsion process
}

\author{
Jiye Fang, ${ }^{\text {a) }}$ Narayan Shama, Le Duc Tung, Eun Young Shin, Charles J. O'Connor, \\ Kevin L. Stokes, Gabriel Caruntu, John B. Wiley, Leonard Spinu, and Jinke Tang \\ Advanced Materials Research Institute, University of New Orleans, New Orleans, Louisiana 70148
}

(Presented on 13 November 2002)

\begin{abstract}
$\mathrm{NiFe}_{2} \mathrm{O}_{4}$ ultrafine powder with high crystallinity has been prepared through a reverse microemulsion route. The composition in starting solution was optimized, and the resulting $\mathrm{NiFe}_{2} \mathrm{O}_{4}$ was formed at temperature of around $550-600{ }^{\circ} \mathrm{C}$, which is much lower than that observed from the solid-state reaction. Magnetic investigation indicates that samples are soft-magnetic materials with low coercivity and with the saturation magnetization close to the bulk value of Ni ferrite. (C) 2003 American Institute of Physics. [DOI: 10.1063/1.1555394]
\end{abstract}

\section{INTRODUCTION}

Magnetic ferrites are a group of technologically important magnetic materials. Recent years, nanometer-sized magnetic ferrites have attracted considerable attention as their physical properties are quite different from those of the bulk. ${ }^{1,2} \mathrm{NiFe}_{2} \mathrm{O}_{4}$ is a typical spin soft-magnetic ferrite and it is extremely interesting to gain its ultrafine powder owing to their broad applications ${ }^{3}$ such as microwave devices. Its preparation by the classical solid-state reaction requires a high calcination temperature and hence induces the sintering and aggregation of particles. ${ }^{4}$ Although there has been a number of reports demonstrating the achievements in wet chemically preparing the $\mathrm{NiFe}_{2} \mathrm{O}_{4}$ nanoparticles through kinds of approaches such as coprecipitation, ${ }^{5}$ sol-gel, ${ }^{6}$ and hydrothermal $^{7}$ methods, it is still worth improving the particles morphology and enhancing the crystallinity at a low calcination temperature. In this work, we applied a reverse microemulsion technique to the fabrication of $\mathrm{NiFe}_{2} \mathrm{O}_{4}$ nanoparticles.

\section{EXPERIMENT}

The starting materials include $\mathrm{Ni}\left(\mathrm{NO}_{3}\right)_{2} \cdot 6 \mathrm{H}_{2} \mathrm{O}$ $(>99.999 \%)$, cyclohexane $(99.9+\%)$, poly (oxyethylene) ${ }_{9}$ nonyl phenol ether (hereafter NP9), all of these chemicals were from Aldrich, U.S.; $\mathrm{Fe}\left(\mathrm{NO}_{3}\right)_{3} \cdot 9 \mathrm{H}_{2} \mathrm{O}(>99.3 \%$, J. T. Baker), ammonium hydroxide (GR, 28-30\%, EM), poly (oxyethylene) ${ }_{x}$ nonyl phenol ether (hereafter NP $x, x=5$ or 9 , from Albright and Wilson Asia Pte Ltd., Singapore).

The procedure of establishing a partial phase diagram at room temperature for the ternary system consisting of cyclohexane, NP5 + NP9, and an aqueous solution has been detailed elsewhere. ${ }^{8}$ To locate the determination between the microemulsion and nonmicroemulsion regions, the aqueous phase was titrated into a mixture of given cyclohexane to surfactant ratio. Thorough mixing of the three components was achieved using a Vortex mixer. Microemulsion compositions appear optically transparent when the size of aqueous droplets is in the range of 5 to $20 \mathrm{~nm}$, due to the fact that the

a) Author to whom correspondence should be addressed; electronic mail: jfang1@uno.edu nanosized aqueous droplets do not cause a substantial degree of light scattering. A series of such demarcation points were obtained by varying the cyclohexane to surfactant ratio. Partial phase diagrams at room temperature for three ternary systems were thus established. They consisted of cyclohexane, NP5 + NP9 (weight ratio: 2:1) and an aqueous phase containing $2.0 \mathrm{M}$ ammonia or $[x] \mathrm{M} \mathrm{Ni}\left(\mathrm{NO}_{3}\right)_{2}$ $+0.10 \mathrm{M} \mathrm{Fe}\left(\mathrm{NO}_{3}\right)_{3}$ ( $x$ varies from 0.05 to 0.20 ), respectively.

The general procedure of powder preparation can be referred to Ref. 8. Two microemulsion compositions were prepared. They all consisted of 67.5 wt \% cyclohexane, 22.5 wt $\%$ NP5/NP9 (weight ratio: $2: 1$ ), and $10.0 \mathrm{wt} \%$ aqueous solution. The aqueous phase contained either $2.0 \mathrm{M}$ ammonia solution, or $[x] \mathrm{M} \mathrm{Ni}\left(\mathrm{NO}_{3}\right)_{2}+0.10 \mathrm{M} \mathrm{Fe}\left(\mathrm{NO}_{3}\right)_{3}$ solution. The concentration " $x$ " was varied from 0.05 to 0.20 to optimize the composition in the final $\mathrm{NiFe}_{2} \mathrm{O}_{4}$ powder. In each time, the reaction was brought about by mixing the two compositions together via vigorously stirring for more than 20 min. To retrieve the precipitates formed in microemulsions, the cyclohexane and surfactant were washed off using ethanol (99.5\%), followed by recovery using centrifugation. Samples were dried under a vacuum at room temperature for at least $20 \mathrm{~h}$.

The as-dried $\mathrm{Ni}-\mathrm{Fe}$-precursors with different $\mathrm{Ni}-\mathrm{Fe}$ ratios were characterized using a thermogravimetric analysis (TGA) (TA Instrument, SDT Q600) at a heating rate of $10{ }^{\circ} \mathrm{C} / \mathrm{min}$ in air. They were then calcined in air at various temperatures up to $900{ }^{\circ} \mathrm{C}$, followed by phase analysis employing an $\mathrm{x}$-ray diffraction (XRD) technique $(\mathrm{Cu} K \alpha$, Philips X'pert-systems). Composition ratio between $\mathrm{Ni}$ and $\mathrm{Fe}$ in the calcined powders was determined based on the relative intensities of major XRD peaks of $\mathrm{NiO}, \mathrm{Fe}_{2} \mathrm{O}_{3}$, and $\mathrm{NiFe}_{2} \mathrm{O}_{4}$. Crystallite size in single phase of $\mathrm{NiFe}_{2} \mathrm{O}_{4}$ was estimated on the basis of line broadening at half maximum of the (311) peak. An $\mathrm{NiFe}_{2} \mathrm{O}_{4}$ particle image was taken from JEOL 2010 transmission electron microscope. Magnetic properties measurement was conducted using a superconducting quantum interference device magnetometer (MPMS-5S Susceptometer from Quantum Design). 


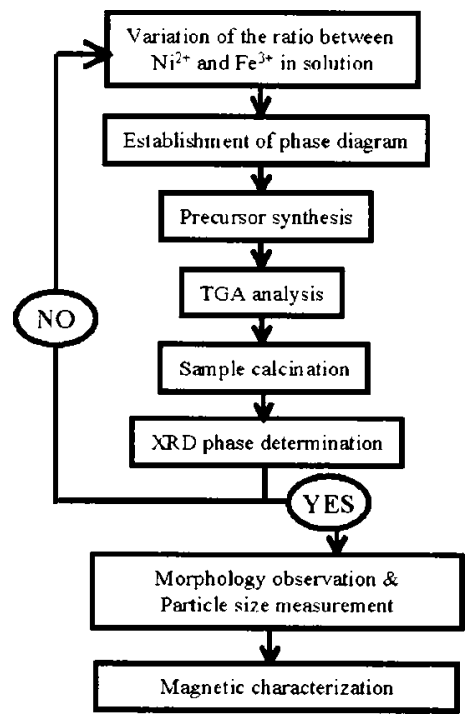

FIG. 1. Flow chart for the investigation of $\mathrm{NiFe}_{2} \mathrm{O}_{4}$.

\section{RESULTS AND DISCUSSION}

\section{A. Formation of $\mathrm{NiFe}_{2} \mathrm{O}_{4}$ precursors}

A coprecipitation between $\left(\mathrm{Ni}^{2+} / \mathrm{Fe}^{3+}\right)$ and excessive ammonia solution was involved in this preparation. Due to the possible complexing interaction between the $\mathrm{Ni}^{2+}$ and $\mathrm{OH}^{-}$during the coprecipitation, the stoichiometric ratio between the starting reagent $\mathrm{Ni}^{2+}$ and $\mathrm{Fe}^{3+}$ (i.e., 1:2 in mol) is not applicable. As to be mentioned later, we actually varied the concentration of reagent $\mathrm{Ni}^{2+}$ from 0.05 to $0.20 \mathrm{M}$ when that of $\mathrm{Fe}^{3+}$ was fixed as $0.10 \mathrm{M}$. The ideal concentration of $\mathrm{Ni}^{2+}$ was thus optimized by considering the XRDdetermined phase ratio in those of calcined $\mathrm{Ni}-\mathrm{Fe}$ oxides as a feedback. The investigation was organized as illustrated in Fig. 1.

To ensure that all the chemical preparations were "transferred" into the "nanoenvironment" in a medium of microemulsions, we have partially established the cyclohexane(NP5/NP9 surfactant) - (aqueous solution) ternary phase diagrams for all the systems containing $2.0 \mathrm{M}$ ammonia solution or various $[x] \mathrm{M} \mathrm{Ni}\left(\mathrm{NO}_{3}\right)_{2}+0.10 \mathrm{M} \mathrm{Fe}\left(\mathrm{NO}_{3}\right)_{3}$ solutions. Figure 2 shows a typical partial ternary phase diagram established at room temperature. The shaded region represents a reverse microemulsion area. Depending on the ratio between $\mathrm{Ni}^{2+}$ and $\mathrm{Fe}^{3+}$ in the starting reagents, the final $\mathrm{Ni}-\mathrm{Fe}$ oxides may contain either single phase of $\mathrm{NiFe}_{2} \mathrm{O}_{4}$, or $\mathrm{NiFe}_{2} \mathrm{O}_{4}+\mathrm{Fe}_{2} \mathrm{O}_{3}$, or $\mathrm{NiFe}_{2} \mathrm{O}_{4}+\mathrm{NiO}$ or other possible compositions. We have carefully examined various XRD patterns derived from $[x] \mathrm{M} \mathrm{Ni}\left(\mathrm{NO}_{3}\right)_{2}+0.10 \mathrm{M} \mathrm{Fe}\left(\mathrm{NO}_{3}\right)_{3}$ solutions in which the $x$ volume was set as $0.05,0.10,0.12$, 0.15 , and 0.20 . By analyzing these XRD patterns, $x$ was optimized as 0.12 . In other words, a starting solution containing $\left[0.12 \mathrm{M} \mathrm{Ni}\left(\mathrm{NO}_{3}\right)_{2}+0.10 \mathrm{M} \mathrm{Fe}\left(\mathrm{NO}_{3}\right)_{3}\right]$ gave a single phase of $\mathrm{NiFe}_{2} \mathrm{O}_{4}$ under present synthetic conditions. Figure 3 shows the TGA trace at a heating rate of $10{ }^{\circ} \mathrm{C} / \mathrm{min}$ in air for precursors prepared using such composition. It exhibited three apparent falls in specimen weight over the temperature ranges from 40 to $180^{\circ} \mathrm{C}$, from 230 to $310^{\circ} \mathrm{C}$, and from 400 to $555^{\circ} \mathrm{C}$. The weight loss covering the first two falls, i.e., at

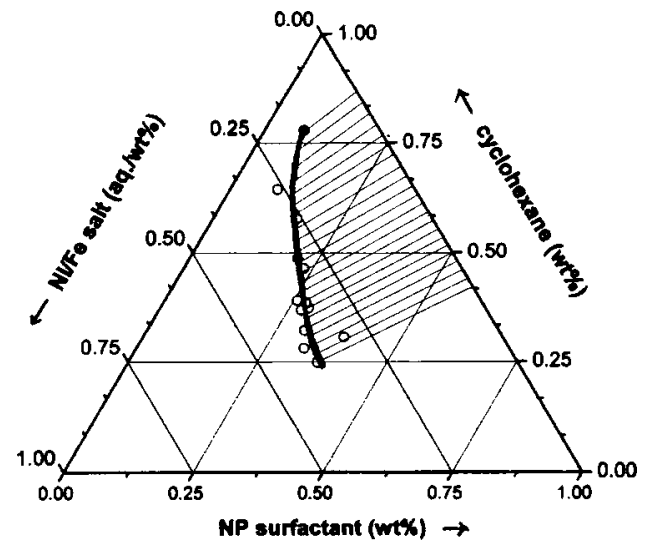

FIG. 2. The partial phase diagram established at room temperature for the ternary system consisting of cyclohexane, NP5/NP9 (weight ratio: 2:1) and aqueous solution of $\left[0.12 \mathrm{M} \mathrm{Ni}\left(\mathrm{NO}_{3}\right)_{2}+0.10 \mathrm{M} \mathrm{Fe}\left(\mathrm{NO}_{3}\right)_{3}\right]$.

temperatures below $310^{\circ} \mathrm{C}$ is believed to be due to the elimination of the residual water and the dehydration of the hydroxides hydrates in the precursors. ${ }^{9}$ The fall in specimen weight over the temperature range from 400 to $555^{\circ} \mathrm{C}$ is related to the decomposition of nickel hydroxides and iron hydroxides, as well as the residues of surfactant. As shown in Fig. 3, the weight loss stops from $\sim 555^{\circ} \mathrm{C}$, indicating the complete formation of $\mathrm{NiFe}_{2} \mathrm{O}_{4}$ at that temperature.

\section{B. $\mathrm{NiFe}_{2} \mathrm{O}_{4}$ powder characterization}

Figure 4 is the XRD pattern recorded at room temperature from the precursor prepared using above composition $(x=0.12)$ and calcined at $600{ }^{\circ} \mathrm{C}$ for $3 \mathrm{~h}$. These peaks are indexed to the cubic $\mathrm{NiFe}_{2} \mathrm{O}_{4}$ phase according to the standard ICDD PDF (Card No. 10-0325). From the XRD line broadening of the (311) peak using the Scherrer equation, ${ }^{10}$ the crystalline sizes were estimated as $11.2 \mathrm{~nm}, 16.9 \mathrm{~nm}$, and $28.8 \mathrm{~nm}$ for the specimens calcined for $3 \mathrm{~h}$ at $600{ }^{\circ} \mathrm{C}, 700^{\circ} \mathrm{C}$, and $800{ }^{\circ} \mathrm{C}$, respectively. These results are in good agreement with those characterized using transmission electron microscopy (TEM) techniques. As demonstrated in Fig. 5, the TEM image of powder calcined at $600{ }^{\circ} \mathrm{C}$ for $3 \mathrm{~h}$ reveals that the discrete particles exist in polyhedron and average crystallite size ranges around $10-15 \mathrm{~nm}$ in diameter with high crystallinity (shown on the top inset). Although both the XRD pat-

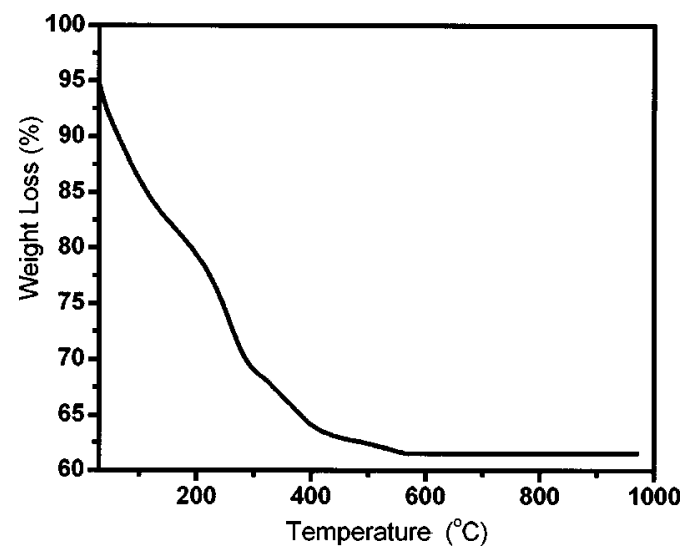

FIG. 3. TGA trace of $\mathrm{N}-\mathrm{Fe}$-hydroxides derived from two microemulsions containing $\left[0.12 \mathrm{M} \mathrm{Ni}\left(\mathrm{NO}_{3}\right)_{2}+0.10 \mathrm{M} \mathrm{Fe}\left(\mathrm{NO}_{3}\right)_{3}\right]$ and $2.0 \mathrm{M}$ ammonia solution. Sample was heated in air in a rate of $10^{\circ} \mathrm{C} / \mathrm{min}$. 


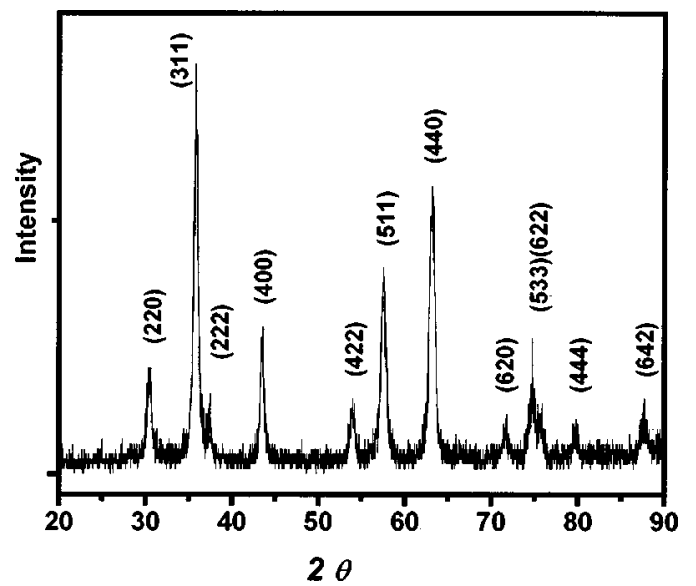

FIG. 4. XRD trace of $\mathrm{NiFe}_{2} \mathrm{O}_{4}$, which was prepared from microemulsions containing $\left[0.12 \mathrm{M} \mathrm{Ni}\left(\mathrm{NO}_{3}\right)_{2}+0.10 \mathrm{M} \mathrm{Fe}\left(\mathrm{NO}_{3}\right)_{3}\right]$ solution and was calcined at $600{ }^{\circ} \mathrm{C}$ for $3 \mathrm{~h}$.

tern recorded from the sample calcined at $550{ }^{\circ} \mathrm{C}$ for $3 \mathrm{~h}$ and the TGA curve indicate that $\mathrm{NiFe}_{2} \mathrm{O}_{4}$ could be formed at $550^{\circ} \mathrm{C}$, we still claim $600^{\circ} \mathrm{C}$ as the formation temperature because the sample calcined at $550^{\circ} \mathrm{C}$ exhibits a relatively low saturation magnetization $(43.0 \mathrm{emu} / \mathrm{g})$ when measured at $300 \mathrm{~K}$. This may indicate that at $550^{\circ} \mathrm{C}$ the sample may still contains a small amount of amorphous impurities, which is undetectable by XRD and TGA. It is worth mentioning the formation temperature of $600^{\circ} \mathrm{C}$ is much lower than that observed from the solid-state reaction. ${ }^{11}$

Figure 6 shows the hysteresis loops of $\mathrm{NiFe}_{2} \mathrm{O}_{4}$ powder calcined for $3 \mathrm{~h}$ at $600{ }^{\circ} \mathrm{C}$ [Fig. 6(a)] and $800{ }^{\circ} \mathrm{C}$ [Fig. 6(b)]. Both samples present soft-magnetic behaviors with coercivity less than $350 \mathrm{Oe}$ at $5 \mathrm{~K}$ (see the insets of Fig. 6). For sample calcined at $800^{\circ} \mathrm{C}$, we obtained saturation magnetization of $54.5 \mathrm{emu} / \mathrm{g}$, which is very close to the bulk value of $55 \mathrm{emu} / \mathrm{g}$ reported for $\mathrm{NiFe}_{2} \mathrm{O}_{4} \cdot{ }^{12}$ For sample calcined at

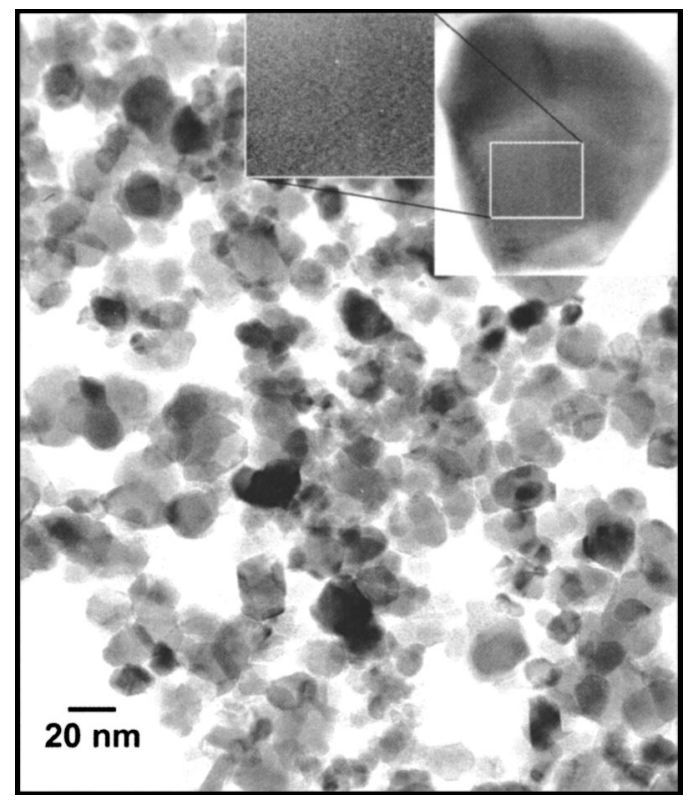

FIG. 5. TEM images of microemulsion-derived $\mathrm{NiFe}_{2} \mathrm{O}_{4}$ (calcined at $600{ }^{\circ} \mathrm{C}$ for $3 \mathrm{~h}$ ).

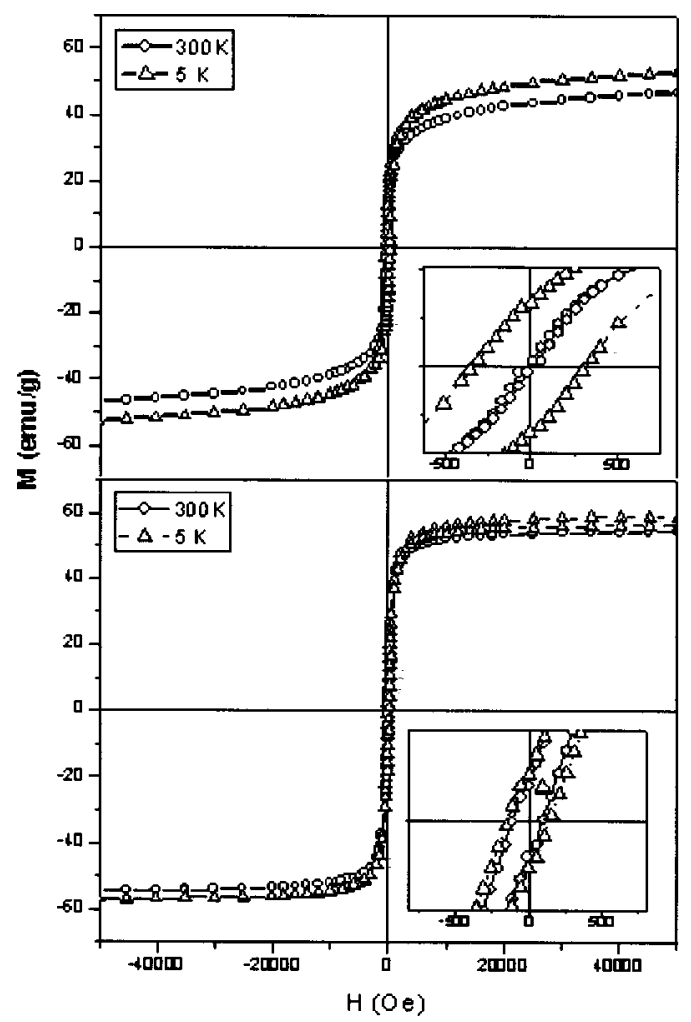

FIG. 6. The hysteresis loops of $\mathrm{NiFe}_{2} \mathrm{O}_{4}$ measured at $300 \mathrm{~K}$ and $5 \mathrm{~K}$. (a) Sample calcined at $600{ }^{\circ} \mathrm{C}$ for $3 \mathrm{~h}$ and (b) sample calcined at $800{ }^{\circ} \mathrm{C}$ for $3 \mathrm{~h}$.

$600{ }^{\circ} \mathrm{C}$, the magnetization measured at $5 \mathrm{~K}$ and $300 \mathrm{~K}$ still increases slightly with increasing magnetic field up to 50 kOe. At the maximum field of $50 \mathrm{kOe}$, we obtained value of magnetization being only $46.9 \mathrm{emu} / \mathrm{g}$ at $300 \mathrm{~K}$. This behavior is believed to be associated with superparamagnetism, as the particle of $<15 \mathrm{~nm}$ is close to the critical size of superparamagnetism for $\mathrm{NiFe}_{2} \mathrm{O}_{4}$. When increasing the particle size by elevating the calcinations temperature, this phenomenon becomes unapparent and even vanished.

\section{ACKNOWLEDGMENT}

This work was supported by the L.A. Board of Regents, NSF/LEQSF (2001-04)-RII-03 and the Air Force, F4962002-C-0060.

${ }^{1}$ G. A. Ozin, Adv. Mater. 4, 612 (1992).

${ }^{2}$ H. Gleiter, Adv. Mater. 4, 474 (1992).

${ }^{3}$ Z. H. Zhou, J. M. Xue, J. Wang, H. S. O. Chan, T. Yu, and Z. X. Shen, J. Appl. Phys. 91, 6015 (2002).

${ }^{4}$ G. Economos, J. Am. Ceram. Soc. 42, 628 (1959).

${ }^{5}$ Y. Shi, J. Ding, X. Liu, and J. Wang, J. Magn. Magn. Mater. 205, 249 (1999).

${ }^{6}$ D.-H. Chen and X.-R. He, Mater. Res. Bull. 36, 1369 (2001).

${ }^{7}$ Y. Xie, Y. Qian, J. Li, Z. Chen, and L. Yang, Mater. Sci. Eng., B 34, L1 (1995)

${ }^{8}$ J. Wang, J. Fang, S.-C. Ng, L.-M. Gan, C.-H. Chew, X. Wang, and Z. Shen, J. Am. Ceram. Soc. 82, 873 (1999).

${ }^{9}$ Y. Ohara, K. Koumoto, T. Shimizu, and H. Yanagida, J. Mater. Sci. 30, 263 (1995); D. L. Perry and S. L. Phillips (Ed.), Handbook of Inorganic Compounds (CRC Press, Boca Raton, 1995), p. 216.

${ }^{10}$ H. P. Klug and L. E. Alexander (ed.), X-ray Diffraction Procedures for Polycrystalline and Amorphous Materials (Wiley, New York, 1954).

${ }^{11}$ W. J. Tomlinson and J. Lilley, J. Mater. Sci. 13, 1148 (1978).

${ }^{12}$ J. Smit and H. P. Wijin, Ferrites (Philips Technical Library, Eindhoven, The Netherlands, 1959), p. 157. 